\title{
Some observations on cooling in laboratory autoclaves
}

\author{
P. H. EVERALL AND C. A. MORRIS \\ From the Public Health Laboratory and Department of Microbiology, Mytton Oak Road, Shrewsbury
}

SYNOPSIS Cooling times for various autoclave loads were recorded using thermocouples. Loads which may be encountered during normal laboratory working require between 17 and 174 minutes to cool to $100^{\circ} \mathrm{C}$ and up to 260 minutes to cool to $95^{\circ} \mathrm{C}$. Such long cooling times had an adverse effect on the nutritive properties of bacteriological culture medium. Observations are made on some factors which influenced the cooling times, and the need for artificially assisted cooling is stressed. Recommendations are given for the safe operation of laboratory autoclaves.

Bottles of liquid removed from an autoclave at the end of a cycle may explode if their temperature has not fallen sufficiently. The Department of Health and Social Security Handbook, Safety in Pathology Laboratories (1972), states 'An autoclave must never be opened until the atmospheric pressure is reached in the chamber, the vent is open and sufficient time has elapsed for the contents to be at a safe temperature. This is usually below $80^{\circ} \mathrm{C}$ '. Unfortunately, few laboratory autoclaves are fitted with any means of measuring the temperature of their contents and, perhaps because of this deficiency, the Department's advice is sometimes mistakenly taken as applying to chamber drain thermometer readings. On neither practical nor theoretical grounds does there seem to be any reason why chamber drain temperatures should be similar to or even parallel with those of load temperatures. The experiments described in this paper were carried out to determine safe cooling times for typical laboratory loads. Coincidentally an attempt was made to determine the effect, if any, of prolonged cooling times on the nutritive qualities of a bacteriological culture medium.

\section{Material and Methods}

A UTOCLAVE

This was a Dent and Hellyer Protector steamheated horizontal autoclave having internal dimensions of $26 \times 26 \times 26$ in $(0.7 \times 0.7 \times 0.7 \mathrm{~m})$. It bears the stock number 1136 in the Department of Health

Received for publication 8 January 1975. and Social Security Stores List. The chamber is ov covered on each of its five sides with a layer of insulating material and the whole is enclosed in an outer jacket of sheet steel. A thermometer is fitted in the chamber drain outside the jacket but proximal to a trap with a 'near-to-steam' element.

THERMOCOUPLES

$\mathrm{NiCr} / \mathrm{NiAl}$ type K PTFE sleeve, part No K76P/2.

ELECTRONIC THERMOMETER COMARK NO $1602^{1}$

This is capable of receiving a signal from only one thermocouple at a time.

RECOR DER

Comark No 404. ${ }^{1}$

LOADS

(1) Forty-eight $20 \mathrm{oz}$ screw cap, winchester-type bottles each containing $400 \mathrm{ml}$ of $2 \%$ agar in saline. ${ }^{2}$ Anti-bumping granules were added to certain bottles for some experiments

or (2) Twenty-four screw cap, winchester quart, bottles each containing two litres of tap water ${ }^{2}$

or (3) Five only $5 \mathrm{oz}$ screw cap, winchester-type bottles each containing $100 \mathrm{ml}$ of nutrient agar

${ }^{1}$ Comark Electronics Ltd, Rustington, Sussex

${ }^{2}$ Divided in equal numbers between both shelves of the autoclave chamber. 
or (4) One two-litre flask containing two litres of nutrient agar and one one-litre flask containing $800 \mathrm{ml}$ of nutrient agar

or (5) As (4) but with the addition of two one-litre flasks each containing $800 \mathrm{ml}$ of nutrient agar.

\section{METHODS}

\section{Load Temperatures}

In order to ensure that the true load temperature was measured the thermocouple was first threaded through a very small hole in the rubber liner of a perforated screw cap and then attached to a glass rod of such a length and in such a position that, when assembled together with its appropriate bottle, the thermocouple was held at approximately the geometric centre of the solution in the bottle (fig 1). The screw cap was tightened in some experiments and slackened off one complete turn in others. Although the thermometer and recorder were each capable of dealing with only one signal at a time, two thermocouples were used in each experiment; these were so wired in circuit with the electronic thermometer that it was possible to change in a moment from one to another by a simple switching mechanism.

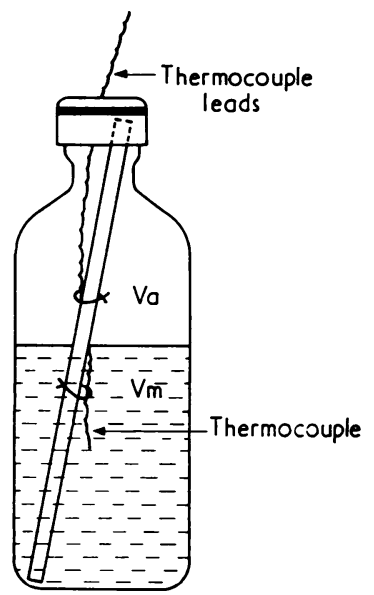

Fig 1 The positioning of a thermocouple in a test load. The fine leads enter through the perforated cap and rubber liner and are then attached to a glass rod so that the thermocouple junction is held centrally in the fluid being autoclaved.

\section{Tests of Nutritive Quality}

The technique used for investigating the changes which may occur in culture medium as a result of long cooling times was as follows: Oxoid Blood Agar Base No 2 (Batch No 318 1625) was reconstituted by adding the appropriate amounts of the solid to volumes of 2 litres and $100 \mathrm{ml}$ of distilled water.
These were then separately sterilized in similar autoclaves which were, at the start of their cycles, at normal room temperature. Both autoclaves were operated at $15 \mathrm{lb}$ per square inch steam gauge pressure for 15 minutes, the 15 minutes being measured from the time the chamber drain thermometer read $121^{\circ} \mathrm{C}$, since this is normal laboratory practice. Cooling of the loads in both autoclaves was monitored by thermocouples, and the agar was removed from the autoclave as soon as its temperature fell to $100^{\circ} \mathrm{C}$. After further cooling in a waterbath both batches were used for preparing layered blood agar plates, the plates from the $100 \mathrm{ml}$ volume being designated batch $\mathrm{A}$ and from the 2 litre volumes batch B. Strains of Staphylococcus aureus, Streptococcus pyogenes, Streptococcus pneumoniae, and Haemophilus influenzae recently isolated in this laboratory were used to inoculate these plates so as to give discrete colonies; in addition, comparative surface viable counts of the streptococci were made on batch $A$ and batch B plates. After incubation overnight measurements of colony diameters were made under the microscope using an eyepiece micrometer and $a \times 2.5$ objective.

\section{Results}

\section{LOAD TEMPERATURES}

Initial experiments on a load of uniform items did not show any constant connexion between the rate of heating or cooling as measured by the thermocouple and its position in the autoclave. For theoretical considerations, in subsequent experiments, load temperatures were always sensed with the thermocouple inserted in a bottle at the centre of the top shelf of the autoclave wherever this was possible. Table I shows details of experimental results and fig 2 reproduces a typical load cooling curve. It will be seen that once the steam to the chamber is turned off, the load cools fairly rapidly until a temperature one or two degrees above $100^{\circ} \mathrm{C}$ is reached. There is then a prolonged period when the temperature remains almost constant: this is followed by a slow but regular fall. The relatively rapid cooling to $102^{\circ} \mathrm{C}$ (fig 2) results from the liquid in the bottles boiling as the pressure in the chamber falls (this is shown in the original temperature tracing as a tremor, although this is not visible in the small-scale sketch reproduced as fig 2). In experiment $\mathrm{i}$ in table $\mathrm{I}$ the time required for the load to cool to $80^{\circ} \mathrm{C}$ was five hours. In subsequent experiments no recordings were made after the load temperature had fallen to $95^{\circ} \mathrm{C}$. The time required for the load to cool to $100^{\circ} \mathrm{C}$ varied from 17 to 174 minutes, and to cool to $95^{\circ} \mathrm{C}$ up to 260 minutes were needed (table I). These times were measured 


\begin{tabular}{|c|c|c|c|c|c|c|c|c|c|}
\hline $\begin{array}{l}\text { Experiment } \\
\text { Number }\end{array}$ & Contents of Load & $\begin{array}{l}\text { State of } \\
\text { Autoclave at } \\
\text { Start }^{1}\end{array}$ & $\begin{array}{l}\text { Room Temp. } \\
\text { at Start } \\
\left({ }^{\circ} \mathrm{C}\right)\end{array}$ & $\begin{array}{l}\text { Max. Temp. } \\
\text { reached } \\
\text { during } \\
\text { Sterilizing } \\
\text { Period } \\
\left({ }^{\circ} \mathrm{C}\right)\end{array}$ & $\begin{array}{l}\text { Sterilizing } \\
\text { Time } \\
(\mathrm{min})\end{array}$ & $\begin{array}{l}\text { Time taken } \\
\text { for Load to } \\
\text { reach } 100^{\circ} \mathrm{C} \\
\text { after 'Steam } \\
\text { off' } \\
(\mathrm{min})\end{array}$ & $\begin{array}{l}\text { Chamber } \\
\text { Drain Temp. } \\
\text { when Load at } \\
100^{\circ} \mathrm{C} \\
\left({ }^{\circ} \mathrm{C}\right)\end{array}$ & $\begin{array}{l}\text { Time taken } \\
\text { for Load to } \\
\text { reach } 95^{\circ} \mathrm{C} \\
\text { after 'Steam } \\
\text { off' } \\
(\mathrm{min})\end{array}$ & $\begin{array}{l}\text { Chamber } \\
\text { Drain Temp. } \\
\text { when Load at } \\
95^{\circ} \mathrm{C} \\
\left({ }^{\circ} \mathrm{C}\right)\end{array}$ \\
\hline i & 48 20-oz screw & Cold & 19 & 120 & 20 & 65 & 50 & 168 & $4 C^{3}$ \\
\hline $\mathrm{ii}^{4}$ & capped & Mod hot & 24 & 121 & 10 & 71 & 80 & 120 & - \\
\hline iii & winchester type & Hot & 28 & 124 & 20 & 102 & 40 & 162 & - \\
\hline iv & bottles ( 24 on & Mod hot & 27 & 120 & 30 & 85 & 48 & 126 & - \\
\hline $\mathbf{v}$ & each shelf) & Cold & 19 & 123 & 30 & 105 & 52 & 160 & 45 \\
\hline vi & each bottle & Cold & 22 & 120 & 20 & 70 & 54 & - & - \\
\hline $\mathrm{vii}^{4}$ & containing $400 \mathrm{ml}$ & Hot & 24 & 118 & 20 & 88 & 60 & - & - \\
\hline viii & of $2 \%$ & Cold & 26 & 116 & 0 & 30 & 85 & - & - \\
\hline ix & agar & Cold & 20 & 116 & $\mathbf{0}$ & 25 & 97 & 108 & - \\
\hline $\mathrm{x}$ & solution & Hot & 24 & 118 & 0 & 60 & 64 & 144 & - \\
\hline$x i$ & $\left\{\begin{array}{l}242.51 \text {. screw } \\
\text { capped bottles }\end{array}\right.$ & Mod hot & 25 & 128 & 20 & 174 & 46 & - & - \\
\hline xii & $\begin{array}{l}\text { each containing } \\
21 \text {. of water }\end{array}$ & Cold & 19 & 122 & 30 & 75 & 92 & 260 & 58 \\
\hline xiii & $\begin{array}{l}\text { One } 21 \text {. conical } \\
\text { flask containing } \\
21 \text {. of agar and } \\
\text { one } 1 \text { l. flask } \\
\text { containing } \\
800 \mathrm{ml} \text { of } \\
\text { agar }\end{array}$ & Cold & 20 & 122 & 15 & 80 & 46 & - & \\
\hline xiv & $\begin{array}{l}\text { Five } 5 \text {-oz } \\
\text { bottles each } \\
\text { containing } \\
100 \mathrm{ml} \text { of } \\
\text { nutrient agar }\end{array}$ & Cold & 20 & 121 & 15 & 17 & 98 & - & \\
\hline & $\begin{array}{l}\text { One } 21 \text {. flask } \\
\text { containing } 21 \text {. of } \\
\text { nutrient agar }\end{array}$ & & & & & & & & \\
\hline $\mathbf{x v}$ & $\begin{array}{l}\text { and } 3 \text { flasks } \\
\text { each containing } \\
800 \mathrm{ml} \text { of } \\
\text { agar }\end{array}$ & Cold & 20 & 121 & 15 & 75 & 43 & - & - \\
\hline
\end{tabular}

Table 1 Autoclave cooling-Dent and Hellyer Protector autoclave

${ }^{1}$ Cold $=$ not previously in use that day

Hot $=$ in use immediately previous to the experiment

Mod hot $=$ in use that same day but not immediately previous to this test

${ }^{2}$ Measured from the time the chamber drain thermometer first recorded a temperature equivalent to that of phase boundary steam at the particular operating pressure, to the moment when the main steam supply was turned off

${ }^{3} \mathrm{~A}$ total of $303 \mathrm{~min}$ were needed for this load to cool to $80^{\circ} \mathrm{C}$, at which point the chamber drain thermometer read $30^{\circ} \mathrm{C}$

'Bottle caps in these two experiments only were finger tight; at all other times they were loose.

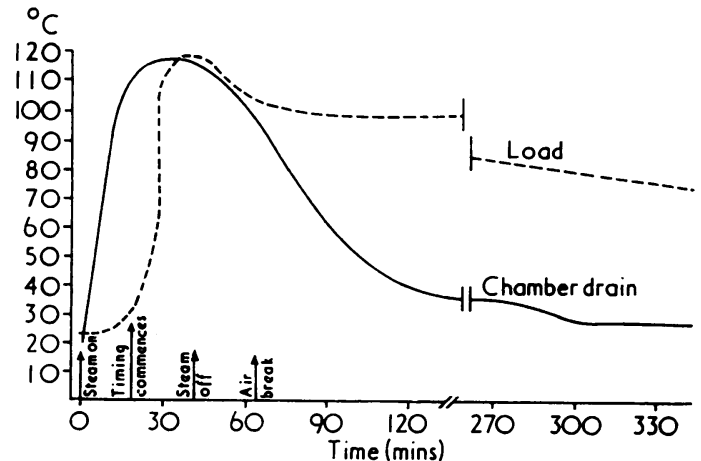

Fig 2 A reproduction of a typical load temperature curve on which readings of chamber drain temperatures have been plotted. The curve is derived from the results of experiment i in table $I$. from the moment when the steam was turned off at $\stackrel{9}{3}$ the end of the 'sterilizing' period.

Screw capped bottles with tight caps cooled more slowly than did bottles with loose caps, particularly ô in the initial stages. This is in accord with the $N$ observation made above on the effect of the load 0 boiling as the chamber pressure falls. However, this $\omega$ difference in the cooling rates progressively declined 2 so that by the time the loosely capped bottles reached a temperature of $100^{\circ} \mathrm{C}$, the temperature within the tight capped bottles was only one degree higher. The addition of anti-bumping granules to the loose capped bottles made no measurable difference to their cooling time.

Not surprisingly, large loads made up of large $\stackrel{\mathbb{Q}}{\Omega}$ units took longer to cool than did small loads of smaller containers (table I, xii and xiv). What had 
not been anticipated so clearly was the effect on cooling of the heat stored in the structural materials of the autoclave. Cooling times were appreciably shorter after a short cycle in an initially cold autoclave than when the autoclave was thoroughly hot from previous use or had undergone a long cycle or when a higher steam temperature had been employed (table $I$, ix and $x$ ).

There was no constant direct relationship between chamber drain temperatures and load temperatures and, for reasons which we shall discuss later, long cooling times were associated with lower final chamber drain temperatures.

TESTS OF NUTRITIVE QUALITY

The colonial appearances of Staph.aureus and $H$. influenzae were unchanged whether the blood agar was made with batch $\mathrm{A}$ medium (short cooling period) or from batch B medium (long cooling period). However both Str. pyogenes and Str. pneumoniae grew more luxuriantly on the batch $\mathrm{A}$ medium than on the batch $B$ medium, and measurements of colony diameter confirmed this. The difference was not such, however, as to reduce the colony counts on medium $B$ as compared with medium A (table II).

\begin{tabular}{|c|c|c|c|c|}
\hline \multirow[t]{2}{*}{ Batch } & \multicolumn{2}{|c|}{$\begin{array}{l}\text { Colony Diameter }(\mathrm{mm}) \\
\text { (mean of } 10 \text { measurements) }\end{array}$} & \multicolumn{2}{|c|}{ Viable Aerobic Counts } \\
\hline & \multicolumn{4}{|c|}{ Str. pyogenes Str. pneumoniae } \\
\hline $\begin{array}{l}\mathbf{A} \\
\mathbf{B}\end{array}$ & $\begin{array}{l}0.65 \\
0.5\end{array}$ & $\begin{array}{l}1 \cdot 1 \\
0.8\end{array}$ & $\begin{array}{l}5.8 \times 10^{7} \\
7.3 \times 10^{7}\end{array}$ & $\begin{array}{l}1.79 \times 10^{7} \\
1.5 \times 10^{7}\end{array}$ \\
\hline
\end{tabular}

Table II Colony diameters and surface viable counts of Streptococcus pyogenes and Streptococcus pneumoniae on blood agar plates of batch $A$ (short cooling period) and batch $B$ (long cooling period)

\section{Discussion}

The pressure reached inside a tightly capped bottle of liquid culture medium on being autoclaved is the resultant of:

(1) the expansion of the liquid as its temperature rises

(2) the increase in air pressure as the temperature rises

(3) the increase in air pressure as a result of the plunger-like effect produced by expansion of the liquid

(4) the increase in saturated vapour pressure of the water as the temperature rises

(5) the increase in the volume of the bottle as the glass expands on rise of temperature.

A volume $(\mathrm{Vm})$ of liquid culture medium, the temperature of which is raised from $t_{1}{ }^{\circ}$ to $t_{2}{ }^{\circ} \mathrm{C}$, will increase by an amount equal to:
$V m\left(t_{2}-t_{1}\right)$ (co-efficient of expansion of the medium)

and this is the volume by which the air space ( $\mathrm{Va}$ ) above the medium will be diminished. If, disregarding the expansion of the glass, the gas laws are applied it can be seen that the original air pressure $P$ in the bottle becomes, as a result of the increase in temperature and decrease in volume, equal to

$$
\frac{P V a}{V a-V m\left(t_{2}-t_{1}\right) \beta} \times \frac{\left(t_{2}+273\right)}{\left(t_{1}+273\right)}
$$

where $\beta$ is the co-efficient of expansion of the medium.

It will be seen from this that the air pressure not only rises directly with the absolute temperature but also increases as $\mathrm{Vm}$ rises relative to $\mathrm{Va}$.

The absolute pressure in the bottle will be given by

$$
\frac{P V a}{V a-V m\left(t_{2}-t_{1}\right) \beta} \times \frac{\left(t_{2}+273\right)}{\left(t_{1}+273\right)}+P s
$$

where Ps is the saturated vapour pressure of water at temperature $t_{2}$. During the 'sterilizing' part of the process this pressure is opposed by the steam pressure in the chamber (Ps).

If a completely sealed bottle of culture medium be inadvertently removed from an autoclave at a temperature in excess of its normal boiling point then both the air pressure and Ps will each be greater than one atmosphere. The hazard of an explosion exists, made more certain the higher $t_{2}$ is above the boiling point of the medium and the fuller the bottle is with culture medium. Even at $80^{\circ} \mathrm{C}$ the air pressure inside a sealed $600 \mathrm{ml}$ bottle containing $500 \mathrm{ml}$ of culture medium will be 1.3 atmospheres. (This figure does not take account of the saturated vapour pressure of water at $80^{\circ} \mathrm{C}$ and assumes a rise from an initial temperature of $20^{\circ} \mathrm{C}$ and a co-efficient of expansion of the culture medium of 0.0003 .)

The pressure in a bottle of culture medium which is not sealed and which is undergoing autoclaving is that of the atmosphere in the autoclave chamber. If it be removed from the autoclave at a temperature above its normal boiling point, the liquid will boil but the bottle will not burst though there remains a danger of scalding.

Having considered these factors, we decided to conduct all our experiments, apart from the early ones, with containers having either loose caps or cotton wool plugs. Furthermore, we feel it would be very wrong to recommend as a routine the autoclaving of media in sealed bottles in the laboratory.

Footnote: In the above calculations, the saturated vapour pressure of water at temperature $t_{1}$, and the variation in the solubility of air in the medium with increase in temperature and pressure, have been disregarded as their effects are minimal. 
While such bottles are regularly used in pharmacies in the preparation of injection fluids, these are usually sterilized in special autoclaves (often fitted with a cooling device). Prolonged cooling, which may be necessary, does not present a problem since the materials being sterilized are not usually as heat labile as are the constituents of bacteriological culture medium.

Where, for any reason, a laboratory must sterilize fluid in sealed containers, the risk of explosion can be minimized by using small bottles and by reducing the volume of liquid in them. (The liquid should, in any case, never exceed two-thirds of the capacity of the container.) Table III shows the effect of the degree of filling of the bottle on the air pressure generated inside it.

\begin{tabular}{ll}
\hline $\begin{array}{l}\text { Percentage of Bottle occupied by } \\
\text { Culture Medium }\end{array}$ & $\begin{array}{l}\text { Factor by which Degree of Filling } \\
\text { alone raises the Air Pressure }\end{array}$ \\
\hline 100 & Bottle bursts \\
90 & 1.8 \\
80 & 1.25 \\
75 & $1 \cdot 18$ \\
66 & $1 \cdot 107$ \\
60 & 1.08 \\
50 & 1.05 \\
40 & 1.03 \\
30 & 1.002 \\
0 & 1.00 \\
\hline
\end{tabular}

Table III Factor $\frac{\mathrm{Va}}{\mathrm{Va}-\mathrm{Vm}\left(\mathrm{t}_{2}-\mathrm{t}_{1}\right) \beta}$ by which the air

pressure inside a bottle is increased by the effect of the degree of filling alone

The bottles are assumed to have been heated from $21^{\circ}$ to $121^{\circ} \mathrm{C}$ and the liquid in them to have a co-efficient of expansion of 0.0005

If it were possible to ensure that fluids removed from a laboratory autoclave were always below $100^{\circ} \mathrm{C}$ and that they were not sealed, then no explosion could occur although the danger of scalding might still remain. However, few laboratory autoclaves are fitted with any means of assessing the load temperature. Chamber drain thermometers (or thermometers inside the free space in the chamber) are essential for the proper processing of a porous load (for which, in any case, a high vacuum autoclave is much to be preferred). In the sterilizing of liquids they only inform the operator when air has been removed from the chamber, as is evidenced by the thermometer showing a reading equivalent to the temperature of phase boundary steam, at the pressure being employed. They do not in the early stages of 'sterilizing', or in the later stages of cooling, in any way indicate load temperature. While it is traditional in laboratories to time sterilizing cycles with their aid, the success of such operations and the rarity of explosions in laboratory autoclave loads is more a measure of the degree of skill founded on experience of the laboratory staff, than of any value which a chamber drain thermometer contributes.

In the initial air displacement stage of a cycle, warm air and condensate flow over the chamber drain thermometer until finally, all air and water having been discharged, the thermometer is in an atmosphere of pure steam. During the cooling stage, once the point has been reached where the pressure in the chamber has fallen and the air-break valve has been opened, the chamber drain thermometer will respond more to the cooling effect of the ambient air than to the heat reaching it by conduction along the chamber drain. It is for this reason that short load cooling times were associated with high final readings of the chamber drain thermometer and vice versa.

The advent of automatic plate pouring machines has made it advisable to prepare and sterilize culture medium in much larger volumes than previously. For this reason we investigated the effect of the associated longer cooling times on the nutritive value of a medium. It is noteworthy that, under the conditions we chose, the large volumes received during the sterilizing period less heat per unit volume per unit of time than did the small volumes. It seems a reasonable assumption, therefore, that the diminution in colony size resulted from the long cooling time needed for the two litre volumes. However, only two such experiments were carried out on both occasions using the same batch of the same medium. Results would probably vary from medium to medium if not from batch to batch and certainly from bacterial species to bacterial species, if not between different strains of the same organism.

The need for rapid cooling in the laboratory autoclave does not in any case stem solely from the effects of long cooling on nutritive values. Long cooling periods reduce the output of plant and buildings, they waste staff time even in a well organized unit, and, perhaps most important of all, tend to produce feelings of frustration which may 우 well lead to an autoclave being opened before it is safe so to do. In view of this, autoclave construction presents something of an anomaly. Present practice $N$ not infrequently is to lag such autoclaves, presumably to reduce heat transfer into the room in which the $N$ autoclave is housed. In an autoclave handling $\underset{\omega}{N}$ porous loads such lagging is advantageous: in a 0 laboratory autoclave it should be replaced by some 0 means of artificially increasing such heat transfer at $\stackrel{\leftarrow}{\Phi}$ the conclusion of the sterilizing stage. The differ- $\stackrel{\infty}{?}$ ences in cooling times required for similar loads $T$ when processed in an autoclave which was sometimes hot and sometimes cold (table I) gives an $\mathbb{D}$ indication of how cooling times could be reduced by $\mathbb{D}$ suitable means of air or water cooling. Spray cooling inside the chamber is not, however, recommended as 
there is evidence that the spray water can be sucked into the bottles as the pressure in them falls. Finally, it should be added that long cooling times of laboratory autoclaves and the absence of means of measuring load temperatures during the 'sterilizing' period make imprecise any statement as to the time temperature relationship to which culture medium has been subjected during sterilization. As a result it might well be found that 'sterilization' times would have to be lengthened somewhat if cooling periods were substantially shortened.

The DHSS handbook, in its recommendation as to what is a safe temperature at which to open an autoclave $\left(80^{\circ} \mathrm{C}\right)$, does not distinguish between the risks inherent in sealed vis-à-vis open containers. As we have shown above, even at $80^{\circ} \mathrm{C}$ the pressure inside a sealed bottle is considerably greater than that of the air around it. If, on the other hand, the load consists of unsealed containers it could well be permissible to open (but not unload) the autoclave as soon as the load temperature falls to $95^{\circ} \mathrm{C}$. The only time it would not perhaps be safe to do this would be when the barometric pressure was unusually low and the autoclave was installed on a high mountain!
Recommendations

For the present:

1 Culture media should not be sterilized in sealed containers. Where for any reason this is unavoidable no bottle should be more than two-thirds full and extra care should be taken on opening the autoclave. 2 All laboratories should possess (or, less preferably, be able to obtain on loan) equipment for measuring the temperature of loads in the autoclave.

3 Laboratories commissioning newly acquired autoclaves should have priority in the obtaining of such equipment.

4 Large loads or loads made up of large unit volumes should preferably be left overnight in a locked autoclave to cool.

For the future:

1 Laboratory autoclaves should be supplied with thermocouples, thermometers, and recorders as standard equipment.

2 Laboratory autoclaves should be equipped with a means of hastening the cooling process.

3 The design and siting of laboratory autoclaves should be the subject of expert investigation. 